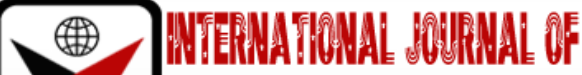

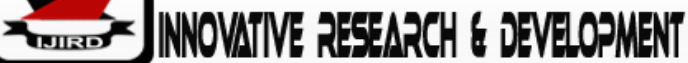

ISSN 2278-0211 (Online)

\section{Understanding How the Distribution of Socio-demographic Factors Impact on Mental Health among University Students in Nigeria}

\author{
Agwu Michael Ezenna \\ Consultant, Department of Public Health, \\ Mother Teresa Public Health Research Center, Nigeria
}

\begin{abstract}
:
Background: The health determinant model indicates that socio-demographic factors influences health status and lifestyle behaviours of any population group in any given nation (Dahlgren \& Whitehead, 1991). Previous studies have suggested the need to examine how these socio-demographic variables are distributed in a given population. However, few studies have undertaken such investigation, especially among university students in developing countries. The aim of this study was to investigate the distribution of some socio-demographic factors among university students in Nigeria and how these variables may relate to depressive symptoms.

Objectives: This study intends to examine the distribution of some socio-demographic variables among university students in Nigeria by gender and ethnicity.

Method: The study was cross sectional. Full time university students were recruited from six universities within three ethnic groups in Nigeria for the study. Data collection was based on an anonymous questionnaire and the sample size was ( $n=1549$ ). Descriptive tests, chi-square tests and analysis of variance (ANOVA) tests were conducted.

Results: Regarding regional characteristics and socioeconomic status, the result indicated sex and ethnicity effects, and irrespective of ethnicity, female students had better monthly income than male students did. The result suggested that students from the Hausa ethnic group reported better monthly income than students from the other ethnic groups. With regard to social support, the result indicated sex*ethnicity effects, where female students from the Hausa and Igbo ethnic groups reported better social support than male students, in contrast to the Yoruba ethnic group, where male students reported better social support than females. With regard to mental health, the result indicated a possible relationship between socio-demographic factors with mental health.

Conclusion: The findings indicated that socio-demographic variables such as age, income status, religious affiliation, social support, gender and ethnicity among others may be a pointer for locating health inequalities among youths in Nigeria and consequently may present an appropriate starting point for health interventions.
\end{abstract}

Keywords: Demographic factors, social factors, health status, ethnicity, gender, mental health, university students Nigeria

\section{Introduction}

The health and well-being of individuals and populations across all age groups is influenced by a range of factors both within and outside the individual's control (Dugdillet al., 2009; Murphy et al., 2009). These multiple factors include socio-demographic, biological, and environmental factors (Trostet al., 2002; Cavillet al., 2006). This study is concerned with socio-demographic variables (e.g. social support, income, age, gender, ethnicity religious affiliation) and how they relate to mental health. 


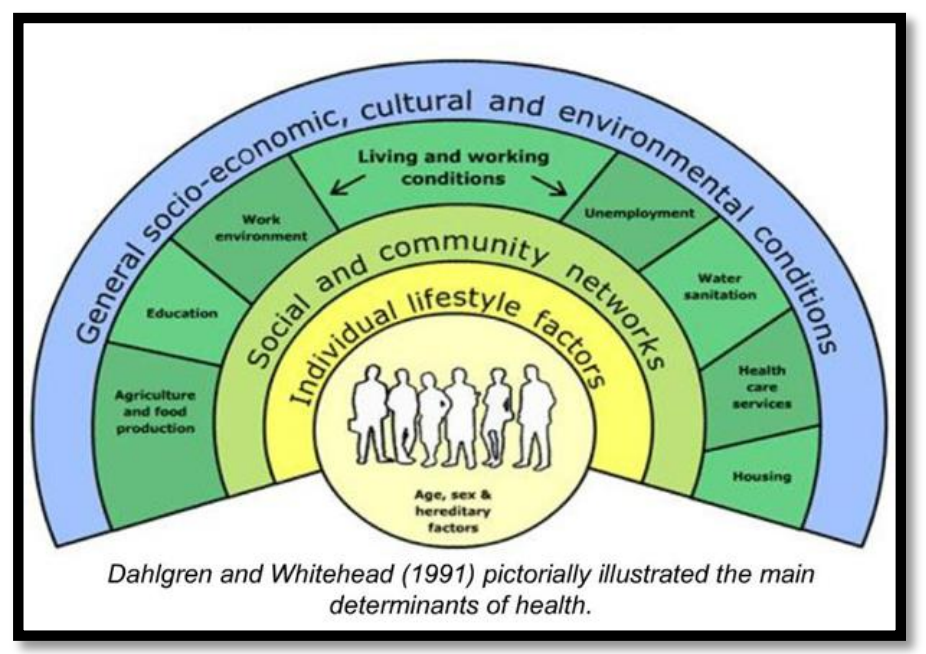

Figure 1: Dahlgren and Whitehead (1991, p.20)

However, the possible relationships between health determinant factors and health status was explained by Dahlgren and Whitehead (1991) in their 'Rainbow Model' which describes the layers of influence on an individual's potential for health (Figure 1). These factors are classified into two: those that are fixed (e.g. Age, sex, ethnicity and genetic factors) on one hand and those that are modifiable factors (e.g. socio-economic, cultural, and environmental conditions). Furthermore, a range of other variables could be considered that are related to each of these layers of the model. For example, variables such as social support and social contact, which would be related to the social and community networks, layer of the model (Figure 1). In other to simplify the social determinants of health model, Cavill et al. (2006) proposed three levels of influence namely: (1) intrapersonal level (2) socio-cultural (interpersonal) and physical-environmental. The intrapersonal level suggests that behaviour is influenced by demographic and biological factors (e.g. gender, age, ethnicity, education, and social class) Cavill et al. (2006). Therefore, the factors of interest to the present study such as gender, region, ethnicity, race, socioeconomic status and, income status, could be aligned to this level (as they are all 'demographic' factors). With regard to the socio-cultural (interpersonal) level, which suggests that behaviour is influenced by factors including social support, social contact from both family members and peers and religious practices.

\section{Background of the Study}

Nigeria is the most populous country in sub-Sahara Africa with an estimated area of $923,773 \mathrm{~km}^{2}$ (National Bureau of Statistics (NBS) 2010; Aregbeshola, 2011), comprising of 36 states and a population of 152 million people (Ucha, 2010; Akuedeet al., 2012). Based on natural landscape, Nigeria is divided into three regions namely: Northern region, Western region and Eastern region, by the intersection of the River Niger and the River Benue (Figure 2) before terminating into the Gulf of Guinea (Philips, 2004). The geographical location of the Federal Republic of Nigeria is on the Gulf of Guinea in the West Africa. It is between Benin in the west and Cameroon in the east, in the north is Chad in the north east and Niger in the north-west.

The diversity of climates observed in Nigeria are aridity in the North, tropical in the center, and equatorial in the South, with a maximum temperature above 32 degrees Celsius in the North (Walker, 2008). The annual rainfall is more in the South 2000 millimeters than in the North 500-700 millimeters (Aregbesola, 2011). Therefore, the Northern region is exposed to a prolonged heat, prolonged drought, and dry seasons, this hash environmental conditions is expected to affect growing of crops, vegetation, and grazing of animals, sources of domestic water and sanitation and farming among others. Consequently, it is assumed that the environmental conditions will affect both the physical health and psychological health of Nigerians living in the Northern region, differently from those living in the other two regions (Terrass \& Benjelloun, 2010). However, no comparative cultural study exists in Nigeria that examined the demographic factors and its relations to mental health among three regions, by gender across any selected population group. Nigeria is multi-ethnic, organized into three major ethnic groups that included Igbo in the East, Yoruba in the West and Hausa/Fulani in the North (Bangdiwalaet al., 2010; Ucha, 2010). Half of the population of Nigerians are Muslim while $40 \%$ of the population are Christians, and the rest $10 \%$ of the population follows the traditional African religion (Paden, 2008; Fafowora, 2011). Although, there is sufficient evidence to show that people's religious orientation, religious affiliations and practice, are associated with psychological health (Ojewumi, 2010). However, no study exists in Nigeria that examines the sociodemographic variables with regard to mental health. 


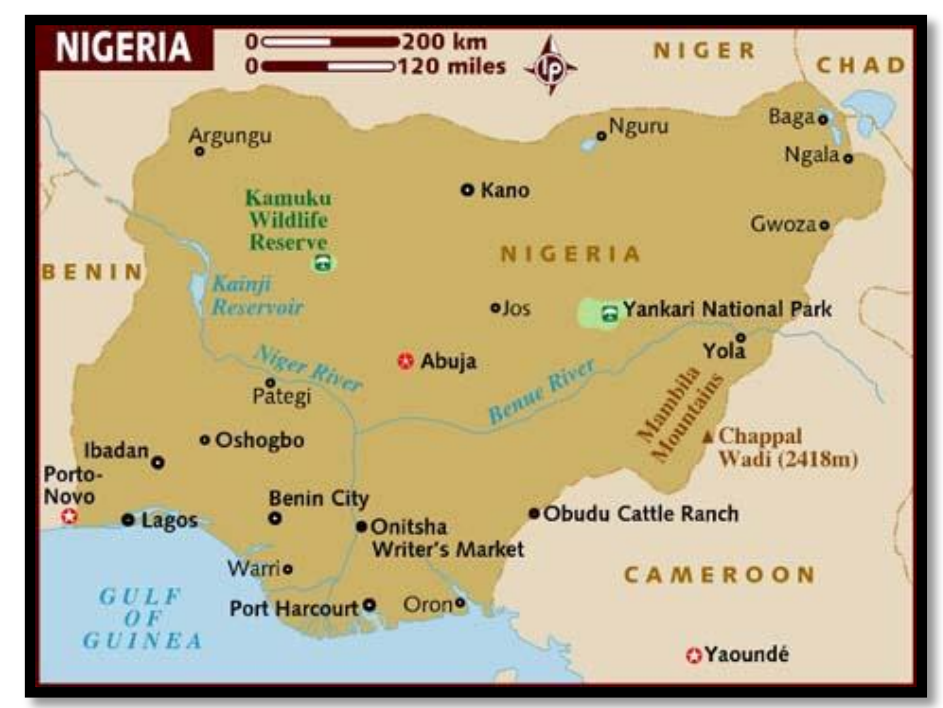

Figure 2: Map of Nigeria Showing the Three Regions by the Intersection of the Niger River and Benue River

Available At: Http//: Mans.Com [Date of Accessed 20th July, 2014]

On the other hand, the health of Nigerians by gender and region has never being considered (Ucha, 2010; Ekpenyong, 2012), despite the evidence that environment and cultural differences contributes to social determinants of health of both individuals and population groups (Dahlgren \& Whitehead, 1991; Bird, 2012). It is assumed that conducting a cross-cultural study in Nigeria for the first time will be a good contribution to literature, by providing a baseline data for future research. Secondly, the findings will provide information to public health departments in Nigeria, to ensure that health services and interventions are expanded and directed to populations and regions, where there is a health need or social need. More so, there is evidence that ethnicity is associated with social, cultural and biological differences that may influence how individuals interpret their health status (2003; Kuk \&Ardern, 2014).Consequently, conducting a study to provide information on the socio-demographic factors, for a population group such as the university students will be of need to the public health community in Nigeria.

\subsection{Understanding Ethnicity, Culture and Race with Regard to the Present Study}

There is no universally agreed definition of ethnicity (Eriksen, 2002 ;), social scientists have several distinct approaches to using this term. According to Bulmer $(1995,54)$ :

'An 'ethnic group' is an identifiable group within a larger society, with a real or putative common ancestry, memories of a shared past, and a cultural focus on one or more symbolic elements which define the groups identity, such as kinship, religion, language, shared territory, nationality or physical appearances.'

However, Eriksen (1993) noted that ethnicity has something to do with classification of people and group relationships. He noted further that ethnicity refers to aspects of relationships among groups that regard themselves as culturally different and are considered by others to be distinct as well. On the other hand, Crawford (2001) observed that ethnic groups are social groups that are divided according to their origin, history, language and culture. He argued further that 'ethnicity is a matter of social organization and beyond questions of empirical cultural differences: it is about the social organization of cultural differences' (p.36). Similarly, Eriksen (1993) pointed out that either ethnicity by definition must arise from a process of social differentiation within a population, which is divided into two or more groups, or by an expansion of system boundaries that create contacts with these groups. In the present study, Nigeria is divided into three ethnic groups, within three regions: Hausa (northern region), Igbo (eastern region), and Yoruba (western region).

This division is supported by the objective definition of ethnicity that is based on the cultural commonness in language, historical background, religion and common territory (Smith, 1986). In Nigeria, each ethnic group has a unique cultural identity distinguished by the markings identified by Smith (1986) such as: unique cultural identity, religious identification, common ancestry, common origin, language, tribal mark, typical dressing patterns, food choices and preparations. Race is said to be 'socially defined but on the basis of physical criteria' whereas an ethnic group is 'socially defined on the basis of cultural criteria' (Eriksen, 2002). However, Bulmer (1995) had earlier observed that 'ethnicity' is a more 'inclusive' term than 'race', because while 'race' is predicted on biological membership of a particular group, ethnic groups are generally seen as having more fluid and blurred boundaries'. Consequently, understanding the ethnic variations and distributions among the university students in the three ethnic groups in Nigeria will help to provide a demographic base line information that may be useful when planning health interventions for students.

\subsection{Review of the Relations between Religiosity and Mental Health}

Religiosity refers to a membership and adherence to the teachings of organized social institutions (Christians, Muslims and Atheism). No study was found that examined how religious affiliation affects mental health of Nigerian youths. The relationship between religiosity and health status has not being fully established. For instance, while the studies of (Franciset al., 2004) provided strong evidence that religiosity and/ or spirituality correlated positively with mental and physical health status. Studies by (Ying, 2009; Leondary \& Gralamas, 2009) reported no association between 
religiosity with mental health or depression. Ying (2009) examined whether religion and spirituality predict well-being among students in an American university, with a convenience sample of $(n=65)$ students.

The result showed that while $49.2 \%$ of the sample identified with organized religion, $43.1 \%$ reported no religious affiliation, while $16.8 \%$ reported to be atheist, agnostic, spiritual or in yoga practice. However, the findings also showed that religious involvements and comfort, and spirituality were not significantly associated with mental health. Based on this study the author argued that although religiosity and spirituality are more content- oriented and involved specific belief systems which in principle, would inform people's behaviour.

However, Ying (2009) postulated that it is possible to hold certain beliefs but not act accordingly in everyday living. In addition, he argued that since only half of the students (49\%) are affiliated with a specific organized religion, it may be possible that religiosity, may not be relevant to the participants. On the other hand, Constantine (2010) recommended that universities should establish counselling centers' and health outreach programs devoted on the health benefit of religion in solving mental health problems.

\subsection{The Effects of Social Support on Mental Health Status}

Sarason et al. (1987, p. 127) defined social support as: 'Having a group of family and friends who provide strong social attachments, being able to exchange helpful resources among family and friends and the feeling of having supportive relationship.' In addition, Sarason et al. (1987) postulated that direct assistance, advice, encouragement, companionship, and expressions of affection are all forms of social support associated with positive outcomes for persons facing life's various dilemmas. There is evidence that social support has positive psychological health impacts, which will be of benefit to university students. However, several factors are reported to be associated with student's social support, such as gender, health status and lifestyles (Abolfotouh et al., 2007).With regard to gender, few studies (e.g. Allgower et al., 2001; Abolfotouh et al., 2007) examined the gender differences in the perception of social support and their findings were controversial. Whereas Allgower et al. (2001) found that students that reported depressive symptoms also reported low social support, in both male and female.

Abolfotouh et al. (2007) found that female students reported higher perceived social support than male students did. They also observed that females naturally are more emotional compared to males, and they are able to share their feelings more freely and readily with friends. By doing so, females perceived that having someone to talk also means having adequate social support. In contrast, males are expected to live up to certain social expectations that have been set and that if they were to share their feelings, it would be perceived as a sign of weakness. Hence, males tend to perceive low social support because they are more likely to feel that they have no one to express their feelings. Allgower et al. (2001) found that low social support was related to students' self-reported mental health problems such as chronic illness, sleep problems and social isolation. On the other hand, Edwards et al. (2001) found that negative social support correlates more with students' physical symptoms and mental health problems than positive social support.

\subsection{The Effect of Socio-Economic Status on Mental Health}

Student's mental health was reported to be associated with income status (Adewuya et al., 2006; Mikolajcyzk et al., 2008). A study by Martins et al. (2004) examined the correlation of mental health and income among students in one university in Brazil, the result showed a positive correlation between student's income status and mental health. Income status and social support plays both directly and indirectly, in affecting health, by restricting the ability to attend hospital and paying for medications, restricting certain lifestyles such as eating healthy foods, living in good environments, be able to pay for gymnasium for regular exercises and some other luxuries that makes one live a happy healthy life.

\subsection{Mental Health Status and Socio-Demographic Factors}

There is evidence that demographic factors (e.g. gender and ethnicity) correlated with students' mental health status (Sabbah et al., 2013; Kuk et al., 2014). On the other hands, studies have shown that the rates of psychological illhealth among university students are increasing and identifying modifiable risk factors for students' psychological health becomes increasingly important, given the persistence of students' psychological health into adulthood (Kaya et al., 2007). Consequently, the mental health condition of university students is a public health issue in both developed and developing countries and many young adults may experience their first psychiatric episode during their time at the university (Bayram and Bilgel, 2008; Adewuya, et al., 2006). In a large study conducted by the American College Health Association National College Health Association [ACHA] (2006), with a population of $(n=47000)$ students from 74 American colleges. The result showed a significant increase of students' mental health, from $8 \%$ to $23 \%$ with $10 \%$ contemplated suicide $14 \%$ reported depression while $63 \%$ reported feeling of hopeless.

Although, several studies examined the factors associated with students' mental health, however, only few studies examined the possible association between socio-demographic factors and mental health variables (e.g., depression, stress, anxiety, anger). The present study intends to examine distribution of socio- demographic factors and their possible influences on mental health especially depression. Gender differences in student's perception of depression have been reported but the findings were controversial. While some studies found that female students reported depression more than male students (e.g., Mikolajcyzk et al., 2008), others (e.g. Bayran \& Bilgel, 2008) found no significant differences between male and female students.

In addition, Lewisohn et al. (1999) reported that race, ethnicity, socio-demographics, culture and religion have been associated with depressive disorders in adolescents. Alternatively, Nolen-Hoeksman (1990) found that higher income countries had a significant gender differences in depression, whereas low-income countries had no significant gender differences in depression. Consequently, Rosenthal and Schreiner (2000) emphasized that the evidence for gender 
and ethnic differences in depression is limited and that more studies with students' sample from different ethnic backgrounds are inconclusive, and recommended for more studies. Student's mental health was reported to be associated with income status (Adewuya et al., 2006; Mikolajcyzk et al., 2008). A study by Martins et al. (2004) examined the correlation of mental health and income among students in one university in Brazil, the result showed a positive correlation between student's income status and mental health.

\section{Research Methods}

\subsection{Consent and Confidentiality}

A letter for approval was presented by hand directly to each Vice Chancellor (VC) of the participating university in Nigeria. The letter contained the required information concerning the research: title, objectives and the data collection techniques. In addition, the researcher made it known in the letter that while there is no harm anticipated in participating in the study, there is equally no benefit that the participants are entitled to either. The letter also explained that the participants consent would be sought before administering the questionnaire, and that their confidentiality will be assured by employing a self-anonymous questionnaire, which does not ask participants name, address or any other form of identification. The letter also explained that the participants have a right to withdraw from the study at any time without any legal implication. The same information was passed to students before data collection with the questionnaire.

\subsection{Sample Size and Sampling Strategy}

The sample for the current study were university students, drawn from universities across Federal Republic of Nigeria. The health survey was administered to $(n=2500)$ students of which $(n=2112)$ were returned. A careful scrutiny showed that $(\mathrm{N}=563)$ was uncompleted due to some respondents did not put their gender, or region making it invalid to be entered for analysis. Finally, $(n=1549)$ respondents completed their questionnaire with the required data and were entered into the SPSS for the analysis, with an overall participation rate of about $84.5 \%$.

\subsection{Multistage Sampling Strategy for Data Collection}

\subsubsection{Stage 1 Sampling of Universities by Categories}

The researcher approached the office of the Federal Ministry of Education in Nigeria and obtained a comprehensive list of all the registered higher education institutions in Nigeria. There are 102 registered universities in Nigeria according to the National University Commission (NUC, 2010), comprising three different categories (Federal, State and Private) universities, within the three main geopolitical zones in Nigeria (Northern, Southern and Eastern) regions that constitute the Federal Republic of Nigeria (Bangdiwalaet al., 2010).

The universities in Nigeria were then stratified into three categories, and all the universities in each category were named, numbered, and put in a different bag. Then the researcher randomly selected two universities each from each of the three university categories. The overall result yielded six universities as follows: two Federal Universities; University of Uyo and Obafemi Awolowo University Ile Ife; two State Universities AkwaIbom State University and Osun State University; two Private Universities Obong University Uyo and Oduduwa University Ikpetumodu.

\begin{tabular}{|c|c|c|c|}
\hline $\begin{array}{c}\text { University } \\
\text { Categories }\end{array}$ & Federal Universities & State Universities & Private Universities \\
\hline $\begin{array}{c}\text { Sampled } \\
\text { Universities }\end{array}$ & $\begin{array}{c}\text { Obafemi Awolowo University } \\
\text { University of Uyo }\end{array}$ & $\begin{array}{c}\text { Osun State University } \\
\text { AkwaIbom State } \\
\text { University }\end{array}$ & $\begin{array}{c}\text { Obon State University } \\
\text { Oduduwa State University }\end{array}$ \\
\hline $\begin{array}{c}\text { Sampled } \\
\text { courses }\end{array}$ & Medicine & $\begin{array}{c}\text { Accounting } \\
\text { Agriculture }\end{array}$ & $\begin{array}{c}\text { Microbiology } \\
\text { Economics }\end{array}$ \\
\hline
\end{tabular}

Table 1: Sampled Universities and Courses of Study

\subsubsection{Stage 2 Sampling of Students Course Study}

The Dean of Students Office (DSO) in participating universities provided the researcher with a list of all courses offered to undergraduate students in each academic semester according to the course level. These courses were stratified according to categories (Federal, State and Private) universities respectively. Then in each university category, the student's courses were adjusted for similarities, by merging different but similar departments together (e.g. microbiology, agricultural sciences, chemistry botany, zoology, physics) were all merged into the department of science so that similarities will be achieved in all university categories. Then, two courses of study with regard to their respective universities were selected at random from a box specific for each university category and the outcome of these random sampling is shown in (Table 1)

\subsubsection{Stage 3 Sampling of Academic Year}

For student's year of study was stratified into (1st, 2nd, 3rd, 4th, 5th, 6th) academic years. However, the cut-off year for the study was fixed at 4th year. In other words, the researcher selected students' participants from academic years (1-4). These cut-off points enabled participants to show similar characteristics. For example, while department of medicine has students up to years (1-6) whereas microbiology and accounting departments have students only and up to 
years (1-4) academic programs. Therefore, fixing a cut-off year at (1-4) ensured identical sample with similar experiences. Other studies (e.g. EL-Gilany et al., 2008) applied similar cut-offs in student's population.

\subsection{Sampling of Participants}

A total of $(n=2500)$ students' sample of both male and female was targeted. To ensure that these samples have equal representation by institution, course and year of study we took the following steps: First, the intended sample $(n=2500 \pm 300)$ was shared equally among the three university categories resulting in ( $n=833)$ participants estimated from each university category (Federal, State and Private). Second, since two universities were recruited from each category, consequently, $(n=833)$ participants were shared into two, allowing a sample of $(n=416)$ from each participating university. Third, since two disciplines were sampled from each participating university, consequently $(\mathrm{n}=$ 416) was shared into two, allowing $(n=208)$ participants to be recruited from each academic discipline. Finally, since four academic years was shortlisted (cut off point) from each academic discipline, consequently, the sample $(\mathrm{n}=208)$ was shared among four academic years, allowing $(n=52)$ students to be recruited from each academic year (e.g. $1,2,3, \& 4)$. All the students in each lecture room were given a questionnaire. The recruitment exercise for each year goes on until the estimated number of participants was met.

\subsection{Statistical Data Analysis}

Students responses to the questions in the present study was transferred to the SPSS statistical package, 20.0 version, which enabled both frequencies and percentages to be computed, which was later presented in a tabular form for easy understanding. All responses where sex and ethnicity were not indicated were automatically excluded from the data analysis. Also, those responses where the respondent ticked more than one alternative was also removed. We checked the scale data first using the Kolmogorov-Smirnov test to ensure that they were acceptably normal before parametric statistics were used. Similarly, Levene's test was used to ensure homogeneity of variance before ANOVAs test were performed. To answer the research questions and achieve the research objectives, three separate tests were conducted: Descriptive statistics, non-parametric tests and parametric tests. Preliminary data analysis of this study was conducted with descriptive tests, which also enabled screening and cleaning the data and to check the entire data set entered into the SPSS for errors. In addition, descriptive statistics made it possible for the description of the characteristics of the sample in percentage, mean, and standard deviation. Chi square test was employed to explore the relationship between categorical variables. Furthermore, the study also employed both the one-way ANOVA, two- way ANOVA to examine the differences and interactions.

\section{Results}

\subsection{Socio-Demographic Characteristics of the Sample}

Table 2 Shows variables used to gauge socio-demographic factors that can influence students' health and well-being. The analysis is presented by sex and by ethnicity and in frequencies and in percentages, with significant effects indicated.

\begin{tabular}{|c|c|c|c|c|c|c|c|c|}
\hline Variables & $\begin{array}{c}\text { Sample } \\
\mathrm{N}=1549\end{array}$ & $\begin{array}{l}\text { Female } \\
\mathrm{N}=848\end{array}$ & $\begin{array}{c}\text { Male } \\
\mathrm{N}=701\end{array}$ & P/ PHI & $\begin{array}{c}\text { Hausa } \\
\mathrm{N}=530\end{array}$ & $\begin{array}{c}\text { Igbo } \\
\mathrm{N}=542\end{array}$ & $\begin{array}{l}\text { Yoruba } \\
\mathrm{N}=477\end{array}$ & P/PHI \\
\hline $\begin{array}{c}\text { Age } \\
<20 \text { years } \\
20-23 \\
\text { years } \\
>23 \text { years }\end{array}$ & $\begin{array}{l}630(41) \\
667(43) \\
252(16)\end{array}$ & $\begin{array}{l}373(44) \\
356(42) \\
119(14)\end{array}$ & $\begin{array}{l}257(37) \\
311(44) \\
133(19)\end{array}$ & $\begin{array}{l}0.003^{*} / \\
.086\end{array}$ & $\begin{array}{c}215(41) \\
216(24) \\
96(15)\end{array}$ & $\begin{array}{c}205(38) \\
254(46) \\
84(16)\end{array}$ & $\begin{array}{c}207(43) \\
198(42) \\
72(15)\end{array}$ & $\begin{array}{c}0.170 / \\
.064\end{array}$ \\
\hline $\begin{array}{c}\text { Monthly } \\
\text { income } \\
\text { High }=> \\
£ 50 \\
\text { Medium } \\
20-£ 50 \\
\text { Low }<£ 20\end{array}$ & $\begin{array}{l}578(37) \\
612(40) \\
357(23)\end{array}$ & $\begin{array}{l}333(39) \\
319(38) \\
197(23)\end{array}$ & $\begin{array}{l}245(35) \\
293(42) \\
163(23)\end{array}$ & $\begin{array}{l}0.001^{*} / \\
.048\end{array}$ & $\begin{array}{l}277(50) \\
145(26) \\
108(24)\end{array}$ & $\begin{array}{l}170(31) \\
242(45) \\
131(24)\end{array}$ & $\begin{array}{l}132(28) \\
225(47) \\
120(25)\end{array}$ & $\begin{array}{c}0.001 \% / \\
.044\end{array}$ \\
\hline $\begin{array}{c}\text { Religious } \\
\text { affiliation } \\
\text { Christianity } \\
\text { Muslim } \\
\text { Others }\end{array}$ & $\begin{array}{l}944(61) \\
228(14) \\
387(25)\end{array}$ & $\begin{array}{c}85(61) \\
133(16) \\
217(23)\end{array}$ & $\begin{array}{c}429(61) \\
85(12) \\
170(27)\end{array}$ & $0.215 / .043$ & $\begin{array}{c}325(61) \\
110(21) \\
95(18)\end{array}$ & $\begin{array}{c}356(65) \\
45(8) \\
161(27)\end{array}$ & $\begin{array}{c}254(56) \\
63(13) \\
128(31)\end{array}$ & $\begin{array}{c}0.001 * / \\
.268\end{array}$ \\
\hline
\end{tabular}

Table 2: Frequency and Percentage (\%) of Socio-Demographic Factors by Sex and Ethnicity

P-Represents the P Value While PHI Indicates Effect Size 
The result indicated that 701(45\%) of the sample were males while $848(55 \%)$ were females. In addition, ethnic characteristics of the sample showed that students were sampled from three ethnic groups: Hausa/Fulani (34\%), Igbo, (35\%) and Yoruba (31\%). With regard to participant's age (Table 2), shows that students in the age group (20-23) years are more compared to students in the other two age groups, whereas students in the oldest age group ( $>23$ years) have the least number of students. On the other hand, Chi-square test for independence indicated a significant association between students reported age and their gender $(p=0.003)$ and the size of the association was much $(\mathrm{Phi}=0.86)$ with female students reporting more on the young age group $<20$ years while the male students are more on the two higher age categories. However, when students age was compared by region, the result showed no significant association between students age group and their region or ethnic origin $\mathrm{p}=0.170$.

With regard to religious affiliations (Table 2), the overall sample indicated more Christians compared to Muslims and one-quarter of the students indicated non- religious affiliation. This finding is important in that in Nigeria religious affiliation is an important denominator often used to group Nigerians as either Muslim North or Christian South, similar to the use of ethnicity or region. On the other hand, a chi-square test showed no significant association between students' religious affiliation and their gender $(\mathrm{p}=0.215$, phi $=0.43)$. This means that the proportion of male students in any of the three possible religious organizations is not significantly different from the proportion of female students in those groups. However, when the analysis was compared by region, the result indicated significant associations, $(\mathrm{p}=$ 0.001), although the effect size was small (.268). As was expected, there were more Muslims in the North, and more Christians in the South especially among the Igbo ethnic group.

With regard to the analysis of students' income status the result indicated significant associations for both gender and region (Table 2). However, looking at the overall sample, the result indicated that less than half of the sample $(37 \%)$ belonged to the highest income group, whereas $(63 \%)$ belonged to the medium and low-income groups. The result indicated that more female students received higher monthly income $(<£ 50)$ than male students. However, the effect size was not much (phi $=0.48$ ), indicating that the difference between rich and poor students was not noticeable. Furthermore, the analysis by region indicated that over half of the Hausa students belong to the highest income group, compared to the combination of the proportion of Igbo and Yoruba in the same group. -

\subsection{Social Support}

With regard to social support, the analysis of the overall sample showed that more than (50\%) of the participants rated their income support to be high. Two-way ANOVA shows significant interaction effect for social support. This effect is shown graphically in (Table 3, Figure 3). The main effects for sex and ethnic indicated that male students' social support was lower than what was available for female students.

\begin{tabular}{|c|c|c|c|c|c|c|c|c|c|c|}
\hline \multirow[b]{2}{*}{ Variable } & \multicolumn{4}{|c|}{ Female (mean (SD) } & \multicolumn{3}{|c|}{ Male (mean (SD) } & Sex"ethnic & Sex & \multirow[t]{2}{*}{ ethnic } \\
\hline & Sample & Hausa & Igbo & Yoruba & Hausa & a Igbo & Yoruba & P-value/ pa & tial Eta sq. & \\
\hline Social support & $\begin{array}{l}5.89 \\
(2.60)\end{array}$ & $\begin{array}{l}6.44 \\
(2.53)\end{array}$ & $\begin{array}{l}5.60 \\
(2.63)\end{array}$ & $\begin{array}{l}6.51 \\
(2.82)\end{array}$ & $\begin{array}{l}5.59 \\
(2.31)\end{array}$ & $\begin{array}{c}5.45 \\
(2.58)\end{array}$ & $\begin{array}{l}5.62 \\
(6.86)\end{array}$ & $0.035 * / .004$ & $0.01 \% .014$ & 0.017 .009 \\
\hline
\end{tabular}

Table 3: Two-Way Anova Showing the Mean (Sd) of Social Support

One-way ANOVA for females showed an ethnic effect $(\mathrm{P}<0.001)$ and post hoc Tukey tests showed that Igbo females was significantly lower than Hausa and Yoruba females $(\mathrm{P}<0.05)$. In addition, the result indicated that Hausa female students' social support was better than what female students among the Igbo and Hausa ethnic groups reported. The graphs presented a clear indication that female students reported social support was better than what was reported by male students in all the ethnic groups. However, in both sex and ethnicity, the effect size was very small ( $\mathrm{r}=.014$ and .009) respectively. Also, one-way ANOVA for male students showed no ethnic effects $(\mathrm{P}<0.066)$ and post hoc Tukey showed no significant differences among male students by ethnicity, also shown graphically in (Figure 3). However, the analysis indicated that whatever type of social support available to male students in the sample, does not have any significant differences when compared across the three ethnic groups. 


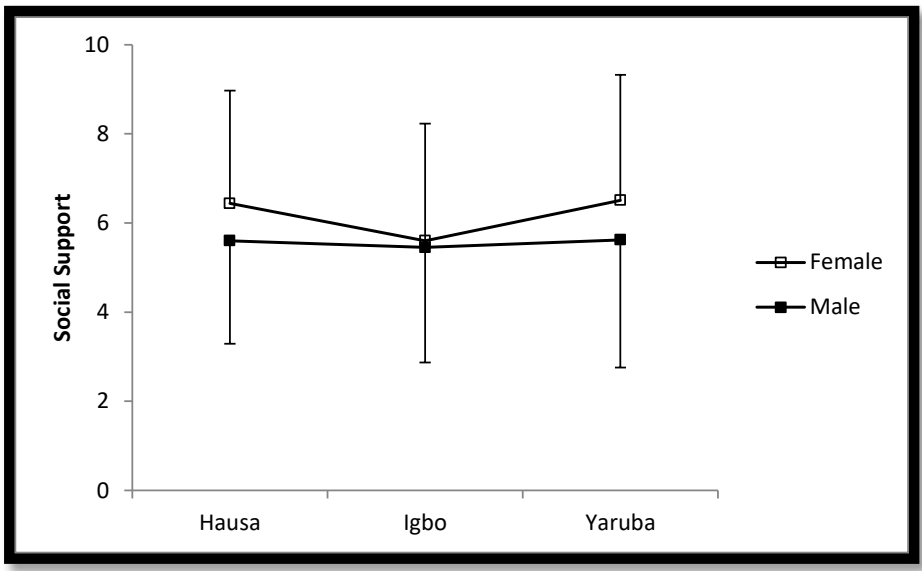

Figure 3: Shows the Sex*Ethnic Main Effects for Social Support are one SD.

The above graph shows one-way ANOVA output plot of sex and ethnic main effects for social support. Error bars

- Igbo female students significantly lower than Hausa and Yoruba females $(\mathrm{P}<0.05)$,

- $\quad$ Male students showed no ethnic effects $(\mathrm{P}>0.05)$.

\subsection{Mental Health Perception}

Table 4 presents the Chi- square analysis of students' mental health indicators by sex and ethnic groups. The result also shows the analysis based on the overall sample. All the analysis is presented by frequency and percentages.

\begin{tabular}{|c|c|c|c|c|c|c|c|}
\hline $\begin{array}{c}\text { VARIABLE } \\
\text { Sample }\end{array}$ & Female & Male & P/PHI & Hausa & Igbo & Yoruba & P/PHI \\
\hline $\begin{array}{c}\text { Depression } \\
\text { Low }<35\end{array}$ & $535(63)$ & $525(76)$ & & $315(59)$ & $396(73)$ & $357(75)$ & \\
$\begin{array}{c}1065(69) \\
\text { High }>35 \\
484(31)\end{array}$ & $313(37)$ & $169(24)$ & & $215(41)$ & $147(27)$ & $120(25)$ & \\
\hline
\end{tabular}

Table 4: Frequency and Percentage (\%) of Mental Health Indicators by Sex and Ethnicity

With regard to depression (Table 4), the result showed that one-third of the total sample of students reported depression. The result also indicated a significant association between male and female students with more females reporting depression compared to male students. The effect size was small $(r=.138)$, indicating no major differences in the actual number of students that suffered depression by gender. In addition, when the analysis was compared by ethnicity, the Chi- square test for independent indicated a significant association between students' reported depression and their ethnic origin. The result indicated that twice as many Hausa students compared to Igbo and Yoruba reported depression. The analyses were further plotted graphically by sex and ethnic in (Figure 4) and the result showed that the Hausa female students are the most depressed and this was followed by the Igbo female students in the sample. However, among the male participants in the study, the Yoruba male students indicated to be the most depressed. It is interesting to note that while there was a significant gender differences in depression among the Igbo and the Hausa ethnic groups, there was no significant differences between the male and female students among the Yoruba ethnic group.

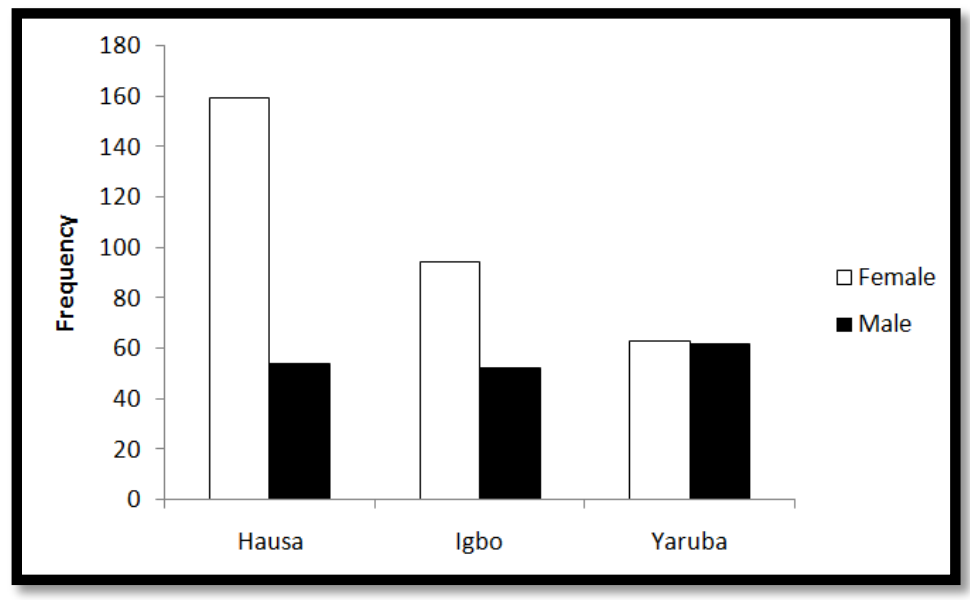

Figure 4: Frequency of Those Reported as Depressed by Gender and Ethnicity 


\section{Discussion of the Results}

\subsection{Distribution of Socio-Demographic Variables in the Study}

In the present study, students' socioeconomic status was measured with monthly income and social support, age, gender, ethnicity and religious affiliation. With regard to monthly income, more than (60\%) of the sample belonged to either the medium or the low-income class. However, interaction effects and main effects for sex and ethnicity, demonstrate that the level of social support and income provided to the students is both sex and ethnicity dependent (Table 2, Table 3, Figure 3) with more female students than male and more Hausa than others having better income and social support. In addition, more Hausa female students reported better social support while Igbo female students had the lowest social support.

The present study is not aware of any other study, which examined the interaction effects of socioeconomic status of students in Nigeria; therefore, the result could not be compared with any other study in Nigeria. However, having more female students on a higher socioeconomic scale in this study than males is a new development in Nigeria and indeed Africa. Previous studies indicated that due to patriarchal African culture, males are more valued than females and females are generally viewed as subordinates to males (Olibieet al., 2013), consequently, the training of boys in school is given more priority, both financially and morally, than girls in the past.

The present study also indicated socioeconomic inequality based on ethnicity, with Hausa ethnic group having a better socioeconomic status than others (Table 2, Table 3 and Figure 2) do. This finding supported previous observations in Nigeria (Aregbesola, 2011). Northern Nigeria (Hausa/ Fulani) ethnic group has being the seat of power and have being ruling Nigeria since the time of independence (Ogbeidi, 2012). Consequently, Northern Nigeria is better funded and with more employment opportunities, more infrastructure and students from e Hausa/ Fulanic ethnic origin are more likely to have loans and other advantages such as social amenities and social support, than other tribes in Nigeria (Aregbesola, 2011).

The study reported more female students than males in the Nigerian universities, and by ethnicity it shows that Igbo ethnic group have more students than any other ethnic group. This may be a true reflection of the Nigeria society, as more women are being encouraged to go to school as a way of women liberation (Olibie et al., 2013). With regard to ethnicity Igbos are reported to have more students as they are seen to be more resilience in the pursuit of education than the other ethnic groups. The study indicated that female students are younger than male students (Table 2), this is equally possible as many male students may be distracted initially from starting school, such as going to learn trade or to help parents in farm work for some years before stating school.

On the other hands on ethnicity, Igbo ethnic group are reported to have the highest number of mature students, those greater than 23 years. This maturity may have a cushioning effect on stress and depression with less attrition of students from the Igbo ethnic group than other ethnic groups, and hence the have the highest number of students' than other ethnic groups. (Table 2). With regard to religious affiliation the study shows that in both gender and ethnicity, more students are affiliated to Christianity than to Muslim. However, these may be attributed to the climate of fear occasioned by the activities of Boko Haram that prohibits all forms of education in Northern Nigeria (Hausa ethnic group), (Adewuya 2006),

\subsection{Distribution of Socio-Demographic Variables and Students Reported Depression}

The prevalence of depression in the current study is high, the overall sample indicated that $30 \%(n=1549)$ of students reported depression. The analysis indicated main effects for sex and ethnicity, with more females irrespective of ethnicity reported depression than males. Other studies have also found that more female students reported depression than male students. For example, in Nigeria, Adewuya (2006) and Aniebue and Onyema (2008), found that female students are more likely than males to experience depression. As expected, the Hausa ethnic group reported more depression than other ethnic groups both by gender and ethnicity (Figure 3). The reason may be due to the consequence of female education by Boko Halam that are abducting and killing especially female students in Northern Nigeria sending waves of terror across the Hausa ethnic group (Adebayo, 2014). In addition, cultural norms where females are expected to do all the home works alone together with their academic work (Omigbodun et al., 2003). With regard to the effects of income on mental health status the study indicated that female students reported higher income status than male students, and similarly, Hausa ethnic groups reported more income status than the other ethnic groups. However, the study indicated that Hausa ethnic group scored higher than other ethnic groups in reporting depressive symptoms despite having the best income status. Consequently, the study concludes that income status is not a complete buffer of depression among students, contrary to the findings that low income and financial problems are both associated with high depression. (Kaya et al., 2007; Gajdosova et al., 2009),

With regard to religious affiliation the study indicated that the sample has more Christians than Muslims (Table 2). As explained earlier, the Hausa ethnic group in the northern region are dominant Muslims while the western region (Yoruba) and the eastern region (Igbo) are dominant Christians. With regard to depression, the study indicated that being a Christian offers more protective mechanism to depression than being Muslim (Figure 3). More so, there is evidence that religious affiliation and activity which is more common to Christianity, show negative relationship with depression and psychological illness (Francis et al., 2004; Ying, 2009; Idehene\&Ojewumi, 2010). With regard to age, the study indicated a significant age differences between male and females with female students reporting younger age group than males (Table 2). However, the study indicated that female students reported more depression than males, suggesting that age is a predictor of depression with young age positively related to depression than old age. On the other hands, there was no significant age differences by ethnicity. 


\section{Conclusion}

This study focused mainly on the distribution of socio-demographic factors and their possible association with mental health among university students in Nigeria. literature evidence indicates that the findings from this study have not been presented in Nigeria, which makes comparison with previous studies difficult. However, the multi-ethnic and multicultural composition of Nigeria, demands an understanding of how the socio-demographic variables are distributed and their interaction with mental health. The result of the study indicated that the prevalence of socio-demographic variables among the sample differs between male and female students (main effect) and most important, these differences exist, between ethnic groups and within the same ethnic group (interaction effects). These findings are unique as it suggests that a linear intervention plan for students in Nigeria will not be effective unless it is based on specific targeted groups.

\section{Limitations of the Study}

Participants for the present study were limited to six universities in Nigeria. It should be expected that the experiences and needs of other students might not be accurately reflected by the investigation. Another caution inherent in the current investigation concerns the homogeneity or lack of diversity, of participants. Consequently, since the participants involved only students in higher institutions, the findings may not reflect the true condition of adolescent youths in Nigeria.

Additionally, since not all the universities in Nigeria were used, there may be variations between universities that may have been be over looked. Consequently, there is a need for more studies among university students in Nigeria. Another limitation of this study may be due to the self-report nature of the instruments. Due to the instruments relying on the participants perceptions, the accuracy of the study could be influenced by imprecise self-reports or mistaken perceptions of a situation. Due to participants, trying to anticipate the socially 'correct' answer rather than honestly, the reliability of instruments is always a concern in self-report situation.

Similarly, the findings of the current study may be limited because of the methodology utilized. Similar to all cross-sectional studies, the present study can only be interpreted based on observed associations of variables, and not on cause and effect relationship with a causal interpretability of results However, In spite of the various limitations anticipated, the current study took adequate steps in the research process to minimize bias. The large number of participants, the high response rate obtained, the multistage method of sampling, and the full geographical representation of students' population, with a rigorous statistical analysis, makes the current study a true reflection of what may be obtainable among university students in Nigeria.

\section{Acknowledgements}

The assistance of the Vice Chancellors of the Obafemi Awolowo University, University of Uyo, AkwaIbom State University, Obong University, Oduduwa University, and Osun State University and the staffs of the IT Center of the University of Gloucestershire England.

\section{References}

i. Akuede, O., Idogho, P.O., \& Imonikhe, J. S. (2012) Increasing access to university education in Nigeria: Present challenges and suggestions for the future. The African symposium, 12(1), 3-12.

ii. Allgower, A., Wardle, J., \& Steptoe, A. (2001). Depressive symptoms, social support, and personal health behaviours in Young men and women. Journal of Health Psychology, 20, 223-227.

iii. Adewuya, A. O., Ola B., A., Aloba, O. O., Mapayi, B. M., \& Oginni, O. O. (2006). Depression amongst Nigerian university students. Journal of Social Psychiatry and Psychiatry Epidemiology, 41; 674-678.

iv. Adebayo, D. O., Summola, A. M., \& Udegbe, I. B. (2008). Subjective wellbeing, work-school conflict and proactive coping among Nigerian non-traditional students. Career Development International, 13, 440-455.

v. Aniebue, P., \& Onyema, G. (2008). Prevalence of depressive symptoms among Nigerian medical undergraduates. Royal Society of Medicine press, 38 (3), 157-158.

vi. Aregbeshola, R. A. (2011). The political, economic and dynamics of Nigeria: A synopsis. Asian Briefing, 39, 1-7.

vii. Bayram, N., \& Bilgel, N. (2008). The prevalence and socio-demographic correlations of depression, anxiety and stress among a group of university students. Journal of Social Psychiatry and Psychiatry Epidemiology, 43, 667672.

viii. Bangdiwala, S. I. Fonn, S. Okoye, O., \& Tollman, S. (2010). Work force resources for health in developing countries. Journal of Public Health Reviews, 32: 296-318.

ix. Bulmer M (1995). The other side of embeddedness: a case -study of the interplay of economy and ethnicity. Journal of Ethnic and Racial Studies, 18 (2), PP.555-567.

x. Cavil, N., Biddle, S. J. H., \& Sallis, J. F. (2006). Health enhancing physical activity for young people: - evidence into practice briefing. London: National Institute for Health and Clinical Excellence, P.301.

xi. Dahlgren, G., \& Whitehead (1991). In Lewis, G. H., Sheringham, J., Kalim, K., \& Crayford J. B. T. (Eds.), Mastering public health: A postgraduate guide to examinations and revalidation. London, Edward Arnold, pp. 277-278.

xii. Dugdill, L., Crone, D. \& Murphy, R. (2009). Physical Activity \& Health Promotion: Evidence-based Approaches to practice. Blackwell Publshing Ltd/

xiii. EL-Gilang, A., Amr, M., Awadalla, N., \& EL-Khawaga, G. (2008). Stress among medical and law students in Mansoura, Egypt. Middle East Journal of Family Medicine, 6 (9). 
xiv. Ekpenyong, C. E., Udokang, N. E., Akpan, E. E., \& Samson, T. K. (2012). Double Burden, Non-communicable diseases and risk factors evaluation in sub-saharan Africa: the Nigerian experience. European. Journal of Sustainable Development, 1 (2), 249-270.

xv. Eriksen T.H. (2002). Ethnicity and Nationalism. London, Pluto Press, PP. 177-53.

xvi. Fafowora, D. (2011). The ethnic factor in Nigeria polities, The Nation Politics. Retrieved on May, 12, 2012 from http:// www.thenationonuneorg.net.

xvii. Francis, L. J, Robbins, M, Lewis C. A. Quigley, C. F., \& Wheeler, C. (2004). Religiosity and general health among undergraduate students: A response. Journal of personality and individual differences, 37(3), 485-494.

xviii. Gajdosova, B. Orosova, O. Geckova, M. A., Tavel, P., \& Van Dijk, J. P. (2009). Personality dimensions, sense of coherence and self-esteem as Risk/protective factors for smoking among university students. Studia Psychologica, 15, 2-3

xix. Idehen, E. E., \& Ojewumi, A. K. (2010). Religiosity and the preventive health behaviour. Journal of LIfePsychologia. Retrieved on April 16, 2012 from, http://readperiodicals.com/201003/19732388//.html

xx. Kaya, M., Genc, M., Kaya, B., \& Pehlivan, E., (2007). Prevalence of depressive symptoms, ways of coping and related factors among medical school and health services higher education student. Turkish Journal of Psychiatry 18(2), 137-146.

xxi. Kuk, J. F., \& Ardern, C. I. (2014). The influence of ethnicity and gender on the association between measured obesity and cardio-respiratory fitness with self-rated overweight, physical activity and health. Perspectives in public Health, 134 (1).

xxii. Lewinsohn, P. M., Rohde, P., Klein, D. N., \& Seeley, J. R. (1999). Natural courses of adolescents major depressive disorder1. Continuity into young adulthood. Journal of the American Academy of Child and Adolescent Psychiatry, 38(1), 56-63.

xxiii. Leondari, A., \& Gialamas, V., (2009). Religiosity and psychological well-being. International Journal of Psychology, 44(4), 241-248.

xxiv. Martins, L., Neto, R., Macedo, P., \& Mari, J. (2004). The mental health of graduate students at the Federal University of Sao Paulo. Brazillian. Journal of medical and Biological Research, 37, 1519-1524,

xxv. Mikolajczyk, R. T, Maxwell, A. E, Naydenova, V, Meier, S., \& Ansari, W. (2008). Depressive symptoms and perceived burdens related to being a student: Survey in three European countries. Journal of Clinical Practice and Epidemiology in Mental Health 4,19

xxvi. National Bureau of Statistics. (NBS, 2011). The review of the Nigerian economy. Retrieved on, June, 20, 2013, from http://www.nigerianstat.gov.ng

xxvii. National university commission NUC. (2013). List of Nigerian universities and years founded. Retrieved on, September, 18, 2013, from http//www.nuc.edu.ng/pages/universities.asp?

xxviii. Nolen-Hoeksema, S. (1990). Sex differences in depression: A prospective study of 372 consecutive admissions to Butabika Hospital, Kampala. East Africa Medical Journal, 49, 16-26.

xxix. Olibie, E. I, Eziuzo, G. O, Enueme, C. K. (2013). Inequalities in Nigerian education sector: Some perspectives for improvement. Journal of Research \& Methods in Education 3 (6).07-14.

xxx. Omigbdum, O. O., Onibokun, A. C, Yusuf B. O., Odukogbe, A. A., \& Omigbodun, A. 0. (2004). Stressors and counselling needs of undergraduate Nursing students in Ibadan, Nigeria. Journal of Nursing Education 43(9).

xxxi. Ogbeidi, M. M. (2012). Political leadership and corruption in Nigeria since 1960: A socio-economic Analysis. Journal of Nigeria studies. 1 (2).

xxxii. Philips, D. A. (2004). Nigeria geography. Philadephia; Chelsea House

xxxiii. Sabbah, I., Sabbah, H., Khamis, R., Sabbah., S., \& Droubl, N. (2013). Health related quality of life of university students in Lebanon: lifestyles behaviours and socio-demographic predictors. Open Access Journal, 5(714), 112

xxxiv. Smith D.A. (1986). The Ethnic origins of nations. Oxford, Blackwell, p.210.

xxxv. Sarason. I. G., Sarason, B. R., Shearin, E. N., \& Pierce, G. (1987). A brief measure of social support: Practical and theoretical implication. Journal of social and personal Relationships, 4, 497-510.

xxxvi. Terrass, F. Benjelloun, M. (2010). The effect of water shortages on health and human development. Perspectives in Public health, 132(5).

xxxvii. Trost, S. G. Owen, N., Bauman, A. Sallis, J., \& Brown, W. (2002). Correlations of adults population in physical activity: review and update. Medcine and Science in Sports and Exercise, 34(12), 1886-2001.

xxxviii. Ucha, C. (2010). Poverty in Nigeria: some dimensions and contributing factors. Global majority. E-Journal, 1(1), pp. 46-56.

xxxix. Piers, L. S., Walker, S. Z., Stoney, R. M., \& O' Dea, K. (2003). Substitution of saturated monounsaturated fat in a 4week diet affects body weight and composition of overweight and obese man. British Journal of Nutrition, 90, 717-727.

xl. Ying, Y., Lee, P. A., \& Tsai, J. L. (2009). Attachment sense of coherence, and mental health among Chines American college students: Variation by migration status. International Journal of Intercultural Relations, 31; 531-544. 